Bi om mi c 02 act i vati on hydroxyl at es a meso-carbon of the por phyrin ring regi osel ect i vel y under $\mathrm{m} I \mathrm{~d}$ condi ti ons

\begin{tabular}{|l|l|}
\hline 著者 & $\begin{array}{l}\text { Yamani shi Kat sunor i, Yai r i Takeshi, Suzuki } \\
\text { Kei suke, Kondo M t sur u }\end{array}$ \\
\hline $\begin{array}{l}\text { j our nal or } \\
\text { publ i cat i on t i t l e }\end{array}$ & Chem cal Communi cat i ons \\
\hline vol une & 49 \\
\hline number & 81 \\
\hline page range & $9296-9298$ \\
\hline year & $2013-08-13$ \\
\hline 出版者 & Royal Soci et y of Chem st ry \\
\hline 権利 & ( C) Royal Soci et y of Chem st ry 2014 \\
\hline URL & ht t p: //hdl . handl e. net /10297/7899 \\
\hline
\end{tabular}




\title{
Biomimic $\mathrm{O}_{2}$ Activation Hydroxylates a meso-Carbon of the Porphyrin Ring Regioselectively under Mild Condition
}

\author{
Katsunori Yamanishi, ${ }^{a}$ Takeshi Yairi, ${ }^{b}$ Keisuke Suzuki, ${ }^{b}$ and Mitsuru Kondo*abc \\ Received (in $X X X, X X X)$ Xth $X X X X X X X X X 20 X X$, Accepted Xth $X X X X X X X X X 20 X X$ \\ DOI: $10.1039 / b 000000 x$
}

The reaction site of the Co(II) porphyrin created by an amide group and coordinating 1,2-dimethylimidazole at the fifth site activated an $\mathrm{O}_{2}$ molecule, and then hydroxylated the mesocarbon of the ligand. The biomimic $\mathrm{O}_{2}$ activation under mild 10 condition is described.

Proximal and distal histidine residues provide the coordination environment for stable $\mathrm{O}_{2}$ fixation $^{1}$ at the heme site of hemoglobin $(\mathrm{Hb})$ and myoglobin $(\mathrm{Mb})$, while proximal and distal-polar residues create a reaction environment for $\mathrm{O}-\mathrm{O}$ bond 15 activation $^{2,3}$ at the heme sites of some metalloenzymes such as cytochrome $c$ peroxidase $(\mathrm{CcP})$, cytochrome $\mathrm{P} 450$ (CYPs), and heme oxygenase (HO) (Fig. 1). $\mathrm{HO}$ activates $\mathrm{O}_{2}$ at the active site, and then hydroxylates the meso-carbon of heme, yielding hydroxy heme in the initial step (Fig. 1c). For activation of the ${ }_{20} \mathrm{O}-\mathrm{O}$ bond at the acctive sites, the so-called "push-pull" mechanism ${ }^{3}$ has been proposed. This is a cooperative effect by electron donation from the proximal residue at the fifth site (push effect) and associations from distal-polar residues to the coordinating substrate (pull effect).

25 Although various porphyrin complexes that mimic the microenvironments have been designed and synthesized, ${ }^{4-6}$ model complexes that activate $\mathrm{O}_{2}$ molecules under mild conditions are still rare. As an important example, Chang and co-workers have shown that their complex [Co ${ }^{\mathrm{II}}$ (npca-por)] ( $\mathrm{H}_{2}$ npca-por $=$ 30 naphthoic acid porphyrin), having a carboxyl group that interacts with $\mathrm{O}_{2}$ bound at the metal center, activates $\mathrm{O}_{2}$ and then oxidizes itself to the oxaporphyrin cation. ${ }^{4}$ Because this reaction did not need coordination of a proximal base, the $\mathrm{O}_{2}$ activation of this system would be caused by the carboxyl group (pull effect).

${ }^{a}$ Graduate School of Science and Technology, Shizuoka University, 836 Ohya, Suruga-ku, Shizuoka 422-8529 Japan.

${ }^{\mathrm{b}}$ Department of Chemistry, Faculty of Science, Shizuoka University, 836 Ohya, Suruga-ku, Shizuoka 422-8529, Japan.

${ }^{c}$ Green Chemistry Research Division, Research Institute of Green Science and Technology, Shizuoka University, 836 Ohya, Suruga-ku, Shizuoka 422-8529, Japan. E-mail: scmkond@ipc.shizuoka.ac.jp

$\dagger$ Electronic supplementary information (ESI) available: Experimental procedures and physical properties. CCCDC 908587 (2) and 908586

(3). For ESI and crystallographic data in CIF or other electronic format see DOI: $10.1039 / \mathrm{b} 000000 \mathrm{x} /$

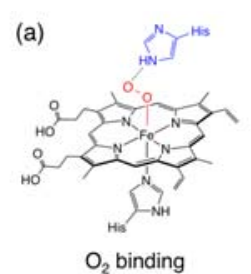

(b)
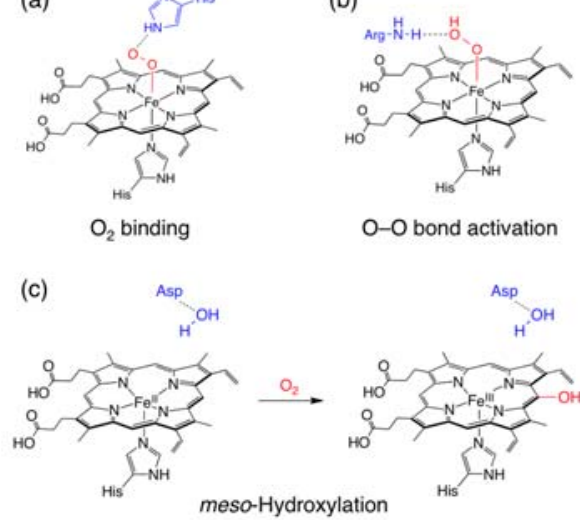

Fig. 1 (a) Proximal and distal histidine for stable $\mathrm{O}_{2}$ fixation observed in active sites of $\mathrm{Hb}$ and $\mathrm{Mb}$. (b) Active site of $\mathrm{CcP}$ created by proximal and distal-polar residues for "push-pull" $\mathrm{O}-$ $\mathrm{O}$ bond activation. (c) The hydroxylation of meso-carbon of heme 40 at the initial step in the catalytic reaction by HO.

We have recently designed a new porphyrin ligand, amtpp, that has an amide group at the ortho-position of a phenyl group of tetraphenylporphyrin (TPP) to mimic the microenvironment created by a distal-polar residue observed in the heme-containing 45 metalloproteins. In a recent report, we have shown that [CoII (amtpp)] (1) converted to new $\mathrm{Co}(\mathrm{III})$ complexes bearing an acyclic pentapyrrole-type ligand, lpp, under air in the presence of nitrogen bases (Scheme 1). ${ }^{6}$ The structure of lpp is shown in this Scheme.
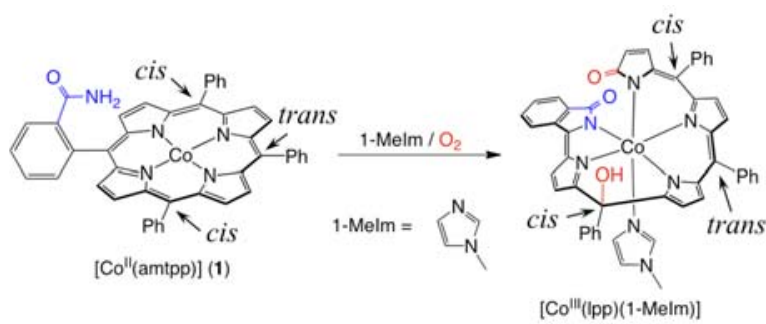

Scheme 1 Conversion of 1 to [Co $\left.{ }^{\mathrm{III}}(\mathrm{lpp})(1-\mathrm{MeIm})\right]$ by reaction with $\mathrm{O}_{2}$ in the presence of 1-MeIm.

We have continued studies on the conversion reaction by using other types of nitrogen bases. Through this work, we have found 
that treatment of $\mathbf{1}$ with 1,2-dimethylimidazole (1,2-Me $\mathrm{Im})$ under air yielded a new Co(III) complex 2 bearing a porphodimethene-type ligand, ampord, whose structure is illustrated in Scheme 2. We report herein the new conversion 5 reaction from 1 to 2 by "push-pull" $\mathrm{O}_{2}$ activation, which mimics the initial step of the catalytic reaction by HO.

A chloroform solution of $\mathbf{1}$ led to a dramatic color change from red to brown in a few hours by addition of $1,2-\mathrm{Me}_{2} \mathrm{Im}$. Diffusion of $n$-hexane into the solution afforded single crystals of

10 [Co ${ }^{\mathrm{III}}$ (ampord) $\left.(\mathrm{OH})\left(1,2-\mathrm{Me}_{2} \mathrm{Im}\right)\right](2)$ in $32 \%$ yield after a few days. As byproduct, $\left[\mathrm{Co}(\operatorname{amtpp})\left(1,2-\mathrm{Me}_{2} \mathrm{Im}\right)_{2}\right] \mathrm{Cl}$ was isolated in $28 \%$ yield (Scheme $\mathrm{S} 1$ in $\mathrm{ESI}^{\dagger}$ ).
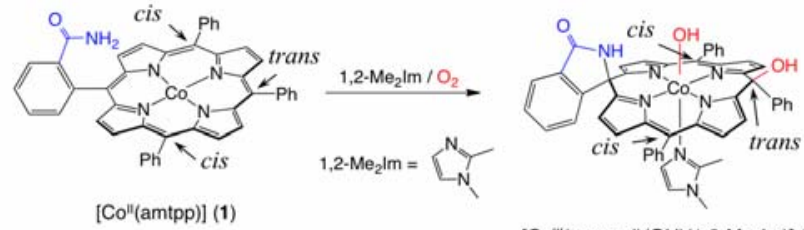

[Co'l'(ampord)(OH)(1,2-Me $\mathrm{Im})](2$

${ }_{15}$ Scheme 2 Conversion of $\mathbf{1}$ to $\mathbf{2}$ by reaction with $\mathrm{O}_{2}$ in the presence of 1,2-Me $2 \mathrm{Im}$.

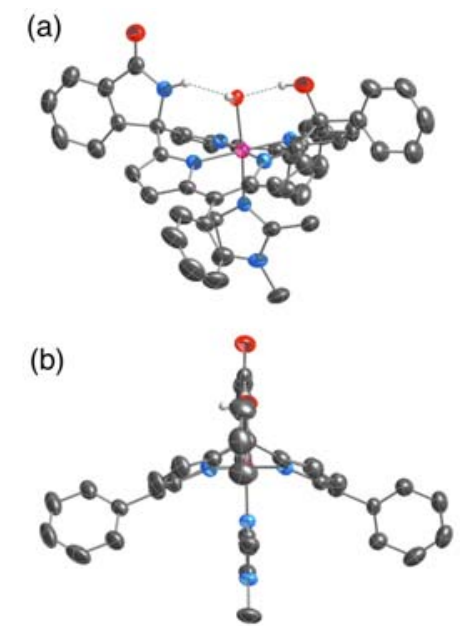

Fig. 2. (a) Thermal ellipsoid plot of 2 at $30 \%$ probability. (b) This view shows the bent structure of $\mathbf{2}$. Hydrogen bonds formed 20 by the coordinating $\mathrm{OH}^{-}$with $\mathrm{NH}$ and $\mathrm{OH}$ groups are illustrated by broken lines. Color code: pink, cobalt; red, oxygen; blue, nitrogen; black, carbon; gray, hydrogen.

The structure of 2 was determined by a single-crystal X-ray diffraction study ${ }^{8}$ (Fig. 2). The meso-carbon atoms in the 25 positions cis and trans to the benzamide group of amtpp are designated as cis-meso-carbon and trans-meso-carbon atoms, respectively, in this paper (Scheme 1,2). The amide nitrogen atom of $\mathbf{1}$ forms a $\mathrm{C}-\mathrm{N}$ bond with the meso-carbon atom of amtpp to yield an oxoisoindoline ring in 2 , while a hydroxyl group is 30 added to the trans-meso-carbon atom of $\mathbf{1}$. The hydroxyl group is regioselectively introduced to the same side of the porphyrin framework where the amide group existed. This is the opposite side from the one that $1,2-\mathrm{Me}_{2} \mathrm{Im}$ occupies. The coordinating $\mathrm{OH}^{-}$at the $\mathrm{Co}(\mathrm{III})$ center forms hydrogen bonds with an NH site 35 of the oxoisoindoline ring $(\mathrm{O} \cdots \mathrm{N}=2.788(6) \AA)$ and the hydroxyl group at the meso-carbon $(\mathrm{O} \cdots \mathrm{O}=2.704(5) \AA)$.

As shown in Fig. 2b, the porphodimethene framework is remarkably bent at the two $\mathrm{sp}^{3}$ carbons. The angle defined by the two conjugating dipyrrin rings is about $118^{\circ}$. The $\mathrm{Co}$ (III) ion is in 40 the plane defined by the four coordinating nitrogen atoms of ampord. The average of the four $\mathrm{Co}-\mathrm{N}$ bond distances is $1.93 \AA$. These bond distances are slightly shorter than those of $\mathrm{Co}-\mathrm{N}$ and Co-O formed between the $\mathrm{Co}$ (III) ion and 1,2- $\mathrm{Me}_{2} \mathrm{Im}$ and the

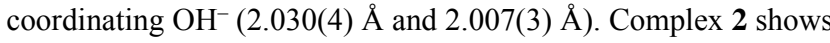
${ }_{45}$ characteristic absorptions at 470 and $502 \mathrm{~nm}$, which are ascribed to the $\pi-\pi^{*}$ transition of their polypyrrole parts. Charts of absorption spectra of $\mathbf{1}$ and $\mathbf{2}$ are shown in Figs. S18 and S19 in the ESI.

We confirmed that $\mathrm{OH}^{-}$at the $\mathrm{Co}(\mathrm{III})$ center and a hydroxyl 50 group at the meso-carbon of 2 come from $\mathrm{O}_{2}$ molecules by ${ }^{18} \mathrm{O}_{2}$ labeling experiments. Fig. 3 shows the electrospray ionizationtime of flight (ESI-TOF) mass spectrum charts of 2 obtained by reaction of 1 with ${ }^{16} \mathrm{O}_{2}$ or ${ }^{18} \mathrm{O}_{2}$ in the presence of $1,2-\mathrm{Me}_{2} \mathrm{Im}$. Complex 2 obtained under ${ }^{16} \mathrm{O}_{2}$ showed an isotope cluster at $\mathrm{m} / \mathrm{z}$ ${ }_{55} 844.2$, assigned to $\left[\mathrm{H}^{+} \cdot 2\right]$, while 2 obtained under ${ }^{18} \mathrm{O}_{2}$ showed the corresponding isotope cluster at $\mathrm{m} / \mathrm{z}$ 848.3. The isotope shift clearly shows that both of the $\mathrm{OH}^{-}$and hydroxyl groups in 2 originate from the $\mathrm{O}_{2}$ molecules.

When the reaction was carried out in tetrahydrofuran ${ }_{60}$ containing 2,000 equiv of $\mathrm{H}_{2}{ }^{18} \mathrm{O}$ under ${ }^{16} \mathrm{O}_{2},{ }^{18} \mathrm{O}$ was not incorporated into the obtained 2 (Fig. S12 in the $\mathrm{ESI}^{\dagger}$ ), showing that the water molecule is not a source of the $\mathrm{OH}^{-}$and hydroxyl group in 2. This result is consistent with the above isotopelabeling experimental results.

(a)

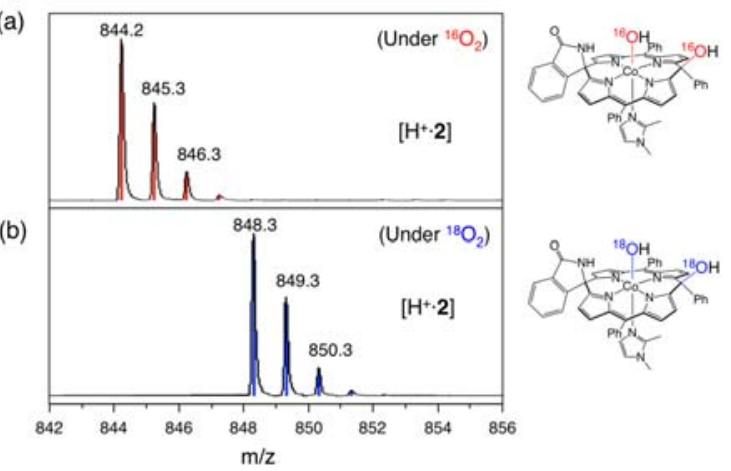

Fig. 3. ESI-TOF mass spectrum charts of 2 obtained by treatment of 1 with 1,2-Me $\mathrm{Im}$ under ${ }^{16} \mathrm{O}_{2}$ (a) and ${ }^{18} \mathrm{O}_{2}$ (b). Each simulation pattern is illustrated by red and blue lines.

Scott and co-workers have reported that porphyrins that have 70 two carboxyl groups near two different meso-carbon atoms that are located in the trans position converted to porphodimethenetype compounds by chemical or electrochemical oxidation. ${ }^{7}$ The metal ions are not necessary in this conversion system. We characterized the electrochemical behavior of $\mathbf{1}$ in the presence of 75 1,2-Me $2 \mathrm{Im}$ using cyclic voltammetry $(\mathrm{CV})$. The oxidation wave was observed at $1063 \mathrm{mV}$ (vs. SCE), which is extremely positive compared with those of Scott's compounds (286-516 mV). Moreover, in contrast to the case of Scott's system, treatment of 1 with 2,3-dichloro-5,6-dicyano-1,4-benzoquinone in $\mathrm{MeOH}$ did 80 not yield $\mathrm{Co}(\mathrm{III})$-ampord-type compounds (page 18 in the $\mathrm{ESI}^{\dagger}$ ), 
showing that the formation of $\mathbf{2}$ from $\mathbf{1}$ is not the result of the simple oxidation of the amtpp framework by $\mathrm{O}_{2}$ molecules without $\mathrm{O}-\mathrm{O}$ bond activation.

The nitrogen base 1,2-Me $\mathrm{Im}$ has a stronger electron-donating 5 ability than other nitrogen bases that yielded Co(III)-lpp-type complexes by treatment with 1 (Fig. S22 in the ESI ${ }^{\dagger}$ ). To examine whether or not the conversion of $\mathbf{1}$ to $\mathbf{2}$ is due to the strong electron-donating ability of the axial ligand, we studied the reaction of 1 with 1,5-dicyclohexylimidazole (1,5-Cy $2 \mathrm{Im})$, which 10 has a similar strong electron-donating ability compared with that of 1,2-Me $2 \mathrm{Im}$. Single-crystal X-ray analysis and elemental analysis clearly showed that the reaction product is not a $\mathrm{Co}(\mathrm{III})-$ ampord-type complex, but $\left[\mathrm{Co}^{\mathrm{III}}(\mathrm{lpp})\left(1,5-\mathrm{Cy}_{2} \mathrm{Im}\right)\right]$ (3) (page 5 and Figs. S3-S5 in the ESI ${ }^{\dagger}$ ). This result means that the formation

15 of $\mathbf{2}$ in this system is not due to stronger electron donation from the axial ligand, but would likely be due to the steric effect of the methyl groups of 1,2-Me2Im.

To obtain insight into the steric effects of the $1,2-\mathrm{Me}_{2} \mathrm{Im}$ on the reactivity of $\mathbf{1}$ toward $\mathrm{O}_{2}$, structures of [Co $\left.\mathrm{Co}^{\mathrm{II}}(\operatorname{amtpp}) \mathrm{B}\right](\mathbf{1} \cdot \mathrm{B})(\mathrm{B}=$ 20 1-MeIm and 1,2-Me $2 \mathrm{Im}$ ) were estimated by density functional theory (DFT) calculations at the B3LYP/6-31G* level. ${ }^{9}$ Their optimized structures are shown in Fig. S29. For 1/1-MeIm, although the phenyl group in the position trans to the benzamide bends down slightly, the conjugating porphyrin framework 25 including four meso-carbon atoms remains planar. In contrast, for 1.1,2- $\mathrm{Me}_{2} \mathrm{Im}$, the porphyrin framework significantly deviates from planarity because of the steric repulsion from the methyl group of 1,2-Me $2 \mathrm{Im}$ in the 2-position. The two cis-meso-carbon atoms bend down from the porphyrin plane, while the trans30 meso-carbon site bends up from the plane. Selective hydroxylation at the trans-meso-carbon atom induced by 1,2$\mathrm{Me}_{2} \mathrm{Im}$ in this system would be due to the approach of the transmeso-carbon atom to the activated $\mathrm{O}_{2}$ species, and the separation of the cis-meso-carbon atom from the activated $\mathrm{O}_{2}$ species. It is 35 likely that terminal oxygen of the activated $\mathrm{O}_{2}$ molecule is a source of hydroxyl group which was introduced to the mesocarbon, and the residual oxygen would be the source of $\mathrm{OH}^{-}$ bound at the $\mathrm{Co}(\mathrm{III})$ site.

In summary, reaction of air-stable $\mathrm{Co}(\mathrm{II})$ complex $\mathbf{1}$ with $\mathrm{O}_{2}$ in 40 the presence of $1,2-\mathrm{Me}_{2} \mathrm{Im}$ was studied. The reaction site, which is created by the amide group and 1,2- $\mathrm{Me}_{2} \mathrm{Im}$ at the fifth position, activated the $\mathrm{O}_{2}$ molecule under mild condition, and then yielded a new $\mathrm{Co}(\mathrm{III})$-porphodimethene-type complex 2. Isotope-labeling experiments showed that $\mathrm{OH}^{-}$at the $\mathrm{Co}(\mathrm{III})$ center and a hydroxyl ${ }_{45}$ group at the meso-carbon of $\mathbf{2}$ originate from the $\mathrm{O}_{2}$ molecule. This reaction mimics the "push-pull" $\mathrm{O}_{2}$ activation observed in heme-containing metalloenzymes. The effects of 1,2-Me $2 \mathrm{Im}$ on the selective hydroxylation at the trans-meso-carbon were preliminary studied by using DFT calculation. The further studies ${ }_{50}$ of the reaction mechanism are currently undergone.

This work was supported by JSPS Fellowship for Young Scientists. We thank K. Terasaki and A. Yamamoto of the Center for Instrumental Analysis in Shizuoka University for support in obtaining the elemental analysis data.

\section{${ }_{55}$ Notes and references}

1 (a) D. M. Kurtz, In Comprehnsive Coordination Chemistry II, Vol. 2 (Eds: L. Que, W. B. Tolman), Elsevier: Tokyo, 2004, p 229-260; (b)
M. F. Perutz, M. G. Rossmann, A. F. Cullis, H. Muirhead, G. Will, A. C. T. North, Nature 1960, 185, 416-422; (c) B. Shaanan, Nature 1982, 296, 683-684; (d) J. R. H. Tame, B. Vallone, Acta Crystallogr. 2000, D56, 805-811; (e) J. C. Kendrew, G. Bodo, H. M. Dintzis, R. G. Parrish, H. W. Wyckoff, D. C. Phillips, Nature 1958, 181, 662-666; (f) J. C. Kendrew, R. E. Dickerson, B. E. Strandberg, R. G. Hart, D. R. Davies, D. C. Phillips, V. C. Shore, Nature 1960, 185, 422-427; (g) U. Flogel, M. W. Merx, A. Godecke, U. K. M. Decking, J. Schrader, Proc. Natl. Acad. Sci. U.S.A. 2001, 98, 735-740; (h) A. Ostermann, I. Tanaka, N. Engler, N. Niimura, F. G. Parak, Biophys. Chem. 2002, 95, 183-193.

2 (a) T. L. Poulos, In The Porphyrin Handbook, Vol 4, (Eds: K. M. 70 Kadish, K. M. Smith, R. Guilard), Academic Press: San Diego, 2000, p 189-218; (b) B. Meunier In Comprehensive Coordination Chemistry II, Vol. 8, (Eds: L. Que, W. B. Tolman), Elsevier: Oxford, 2004, p 261-280; (c) T. L. Poulos, S. T. Freer, R. A. Alden, S. L. Edwards, U. Skogland, K. Takio, B. Eriksson, N.-H. Xuong, T. Yonetani, J. Kraut, J. Biol. Chem. 1980, 255, 575-580; (d) M. A. Miller, A. Shaw, J. Kraut, Nature Struct. Biol. 1994, 1, 524-531; (e) P. R. Ortiz de Montellano, K. Auclair, In The Porphyrin Handbook, Vol. 12 (Eds: K. M. Kadish, K. M. Smith, R. Guilard), Academic Press: San Diego, 2000, p 183-210; (f) T. Matsui, M. Furukawa, M. Unno, T. Tomita, M. Ikeda-Saito, J. Biol. Chem. 2005, 280, 2981-2989; (g) M. Unno, T. Matsui, M. Ikeda-Saito, Nat. Prod. Rep. 2007, 24, 553570.

3 (a) Y. Watanabe, In The Porphyrin Handbook, Vol. 4 (Eds: K. M. Kadish, K. M. Smith, R. Guilard), Academic Press: San Diego, 2000,

85 p 97-117; (b) M. Sono, M. P. Roach, E. D. Coulter, J. H. Dawson, Chem. Rev. 1996, 96, 2841-2887.

4 C. K. Chang, G. Avilés, N. Bag, J. Am. Chem. Soc. 1994, 116, 12127-12128

5 (a) J. P. Collman, R. Boulatov, C. J. Sunderland, L. Fu, Chem. Rev. 2004, 104, 561-588; (b) A. L. Balch, Coord. Chem. Rev. 2000, 200202, 349-377; (c) J. P. Collman, R. R. Gagne, R. R. T. R. Halbert, J. C. Marchon C. A. Reed, J. Am. Chem. Soc., 1973, 95, 7868-7870; (d) J. P. Collman, R. R. Gagne, C. A. Reed, W. T. Robinson, G. A. Rodley, Proc. Nat. Acad. Sci. USA, 1974, 71, 1326-1329; (e) G. E. 95 Wuenschell, C. Tetreau, D. Lavalette, C. A. Reed, J. Am. Chem. Soc. 1992, 114, 3346-3355; (f) J. D. Soper, S. V. Kryatov, E. V. RybakAkimova, D. G. Nocera, J. Am. Chem. Soc. 2007, 129, 5069-5075; (g) J.-G. Liu, Y. Naruta, F. Tani, Chem. Eur. J. 2007, 13, 6365-6378; (h) J.-G. Liu, T. Ohta, S. Yamaguchi, T. Ogura, S. Sakamoto, Y. Maeda, Y. Naruta, Angew. Chem. Int. Ed. 2009, 48, 9262-9267; (i) I. Hijazi, T. Roisnel, M. Fourmigué, J. Weiss, B. Boitrel, Inorg. Chem. 2010, 49, 3098-3100; (j) M. T. Kieber-Emmons, M. F. Qayyum, Y. Li, Z. Halime, K. O. Hodgson, B. Hedman, K. D. Karlin, E. I. Solomon, Angew. Chem. Int. Ed. 2012, 51, 168-172.

1056 K. Yamanishi, M. Miyazawa, T. Yairi, S. Sakai, N. Nishina, Y. Kobori, M. Kondo, F. Uchida, Angew. Chem. Int. Ed. 2011, 50, 6583-6586.

7 (a) M. Harmjanz, H. S. Gill, M. J. Scott, J. Am. Chem. Soc. 2000, 122, 10476-10477; (b) M. Harmjanz, M. J. Scott, Chem. Commun. 2000, 397-398; (c) M. Harmjanz, H. S. Gill, M. J. Scott, J. Org. Chem. 2001, 66, 5374-5383; (d) H. S. Gill, M. Harmjanz, J. Santamaría, I. Finger, M. J. Scott, Angew. Chem. Int. Ed. 2004, 43, 485-490.

8 Crystallographic data have been deposited with the Cambridge Crystallographic Data Centre (CCCDC 908587 (2) and 908586 (3)) and can be obtained via www.ccdc.cam.ac.uk/ data_request/cif. Single Crystal Data; $2 \cdot 2 \mathrm{CHCl}_{3}: \mathrm{C}_{52} \mathrm{H}_{40} \mathrm{Cl}_{6} \mathrm{CoN}_{7} \mathrm{O}_{3}, M^{-}=1082.58$, monoclinic, $P 2_{1} / \mathrm{n}, a=10.7642(5) \AA, b=20.7043(12) \AA, c=$ 22.5542(12) $\AA, \beta=96.087(3)^{\mathrm{o}}, V=4998.2(5) \AA^{3}, T=293 \mathrm{~K}$, reflections collected/unique reflections/parameters refined: $31876 / 8708 / 757, R_{\text {int }}=0.0556$, final $R_{1}=0.0777(I>2 \sigma(I)), \mathrm{w} R_{2}=$ 0.1395 (all data); $3 \cdot 3.25 \mathrm{CHCl}_{3}: \mathrm{C}_{63.25} \mathrm{H}_{55.25} \mathrm{Cl}_{975} \mathrm{CoN}_{7} \mathrm{O}_{3}, M=1366.03$ triclinic, $P \overline{1}, a=12.8053(7) \AA \AA, b=12.8800(6) \AA, c=21.7874(17) \AA$, $\alpha=87.958(6)^{\circ}, \beta=80.671(6)^{\circ}, \gamma=62.793(4), V=3150.6(4) \AA^{3}, T=$ $173 \mathrm{~K}$, reflections collected/unique reflections/parameters refined: $20445 / 10799 / 1018, R_{\text {int }}=0.0364$, final $R_{1}=0.0538(I>2 \sigma(I)), \mathrm{w} R_{2}=$ 0.1138 (all data)

9 Wavefunction, SPARTAN '04 for Windows, Wavefunction Inc,Irvine, CA USA, 2004. 